\title{
Extrahepatic Bile Duct Papillary Adenoma
}

National Cancer Institute

\section{Source}

National Cancer Institute. Extrahepatic Bile Duct Papillary Adenoma. NCI Thesaurus. Code C5849.

An adenoma that arises from the extrahepatic bile ducts. It is characterized by the presence of a papillary growth pattern. 